\title{
ANALISIS PENDAPATAN USAHA TANAMAN HIAS (Studi Kasus UD. Rahma Nurseri di Desa Bangunsari Kabupaten Muna)
}

\author{
Supiani $^{1}$, La Sinaini ${ }^{2}$ \\ Agribisnis Sekolah Tinggi Ilmu Pertanian Wuna Raha \\ email: lasinaini81@gmail.com
}

\begin{abstract}
ABSTRAK
Perkembangan usaha tanaman hias di berbagai daerah di Indonesia telah menjadi sumber pendapatan pelaku usaha tanaman hias, sehingga turut berkontribusi terhadap pertumbuhan ekonomi Bangsa. Penelitian ini bertujuan untuk mengetahui tingkat pendapatan pada usaha tanaman hias “UD. Rahma Nurseri” di Kabupaten Muna. Penelitian ini dilaksanakan pada bulan Januari 2019 sampai bulan Maret 2019. Lokasi penelitian ini ditentukan secara "purposive" (sengaja) dengan pertimbangan satu-satunya usaha tanaman hias yang berkembang di Kota Kabupaten Muna. Analisis data yang digunakan dalam penelitian ini menggunakan analisis pendapatan. Hasil penelitian menunjukkan pendapatan usaha tanaman hias "UD. Rahma Nurseri" memberikan keuntungan sebesar Rp. 3.250.000 perbulan dengan biaya operasional usaha sebesar Rp. 7.680.000 perbulan. Tingkat keleyakan usaha ini yaitu sebesar $(1,9)$ yang berarti setiap pengeluaran sebesar Rp 1 akan memberikan pendapatan sebesar Rp 0,9 .
\end{abstract}

Kata kunci: pendapatan, usaha, tanaman hias

\section{PENDAHULUAN}

Perkembangan dunia usaha dewasa ini semakin pesat. Hal ini ditandai dengan semakin maraknya perusahaanperusahaan baru yang muncul dengan beraneka ragam jenisnya. Hal ini menimbulkan semakin ketatnya persaingan di pasar atau di dunia usaha. Usaha agribisnis tanaman hias saat ini sedang berkembang. Tanaman hias berperan dalam pembangunan sektor pertanian di Indonesia. Khususnya pembangunan agrowisata. Perkembangan agrowisata yang memanfaatkan usaha pertanian sebagai objek wisata membuat bisnis tanaman hias memiliki prospek yang bagus untuk dikembangkan.

Semakin majunya ilmu pengetahuan dan teknologi maka semakin tinggi pula tingkat kepuasan masyarakat dalam memenuhi kebutuhan hidupnya sehingga menuntut pendapatan yang tinggi pula.Terutama dalam pemuasan selera dan pola pikir yang terus meningkat. Begitu halnya dengan kebutuhan akan kesejukan dan kenyamanan dalam lingkungan tempat tinggal. Keindahan tanaman hias saat ini seolah-olah sudah menjadi daya tarik tersendiri bagi sebagian masyarakat yang memang menggemari tanaman hias, atau sekedar menjadikan tanaman hias sebagai pelengkap keindahan disetiap sudut halaman rumah, ibarat dunia mode selalu saja muncul trend tanaman-tanaman hias baru yang menggantikan jenis tanaman yang lama, tentu setiap jenisnya memiliki ciri khas tersendiri.

Perkembangan usaha tanaman hias di berbagai daerah di Indonesia telah menjadi salah satu pusat pertumbuhan ekonomi yang cukup penting. Karena tidak hanya dilakukan atas dasar aktivitas hobi, melainkan dilakukan secara komersial yang mampu menggerakkan pertumbuhan industri barang dan jasa.Usaha tanaman hias pada saat ini adalah usaha yang sudah mulai digeluti 
oleh masyarakat khususnya di daerah Kota Raha Kabupaten Muna.

Tanaman hias merupakan tanaman yang ditanam diluar atau didalam ruangan untuk menciptakan kesan keindahan dan daya tarik pada suatu objek dan memiliki berbagai macam jenis mulai dari tanaman hias berbunga sampai tanaman hias yang berbentuk unik. Bentuk tanaman ini sangat beraneka ragam dan masingmasing tanaman memiliki daya tarik tersendiri untuk layak dikoleksi. Manfaat bagi kehidupan manusia baik secara langsung maupun tidak lagsung yaitu misalnya untuk mengurangi debu. Jika dalam suatu ruangan di dalam rumah terdapat tanaman hias hal itu akan bermanfaat untuk dapat meningkatkan kelembaban suhu udara sehingga bisa untuk mengurangi jumlah debu. Hal ini akan menjauhkan kita semua dari berbagai macam jenis penyakit khususnya yang berhubungan dengan pernapasan. Melihat tanaman hias yang cantik dan indah akan mengurangi rasa stress yang sedang dialami baik itu karena adanya masalah kantor ataupun yang lainnya, sebab tanaman hias dapat menenangkan fikiran karena bentuknya yang indah dan unik. Tanaman hias dapat dipakai sebagai hiasan, bahkan sekarang tanaman hias sering dijumpai di ruang kerja untuk menambah suasana ruangan lebih nyaman selama dalam bekerja.

Salah satu usaha tanaman hias komersial yang ada di Kota Raha saat ini adalah Usaha Tanaman Hias "Rahma Nurseri". Tanaman yang dijual oleh perusahaan tersebut merupakan hasil belanja tanaman yang dilakukan secara teratur maupun permintaan konsumen. Berdasarkan wawancara awal pada pemilik usaha tanaman hias "Rahma Nurseri” di kota Raha, pendapatannya mengalami peningkatan dikarenakan banyaknya minat masyarakat akan tanaman hias saat ini.

\section{METODE PENELITIAN}

Penelitian ini dilaksanakan pada usaha tanaman hias "UD. Rahma Nurseri" yang bertempat di Desa Bangunsari, Kabupaten Muna pada Bulan Januari 2019 sampai dengan Bulan Maret 2019. Data yang digunakan dalam penelitian ini yaitu data primer yang bersumber dari wawancara langsung dengan pengusaha, pemilik usaha dan pekerja tanaman hias dengan bantuan kuisioner yang telah dipersiapkan. Data yang di peroleh selanjutnya terlebih dahulu di tabulasi lalu dianalisis dengan menggunakan analisis pendapatan. Sebelum diperoleh pendapatan usaha, maka dilakukan analisis biaya yaitu mengidentifikasi biaya variabel dan biaya tetap usaha tanaman hias. Adapun rumus yang digunakan untuk menghitung biaya menurut Soedarsono (1992); Soekartawi (1990); DEWANTI \& Sudarman (2001) yaitu sebagai berikut:

$$
\mathrm{TC}=\mathrm{FC}+\mathrm{VC}
$$

dimana TC adalah total biaya, FC adalah biaya tetap, dan VC adalah biaya tidak tetap. Setelah diketahui total biaya, maka selanjutna dilakukan analisis penerimaan usaha tanaman hias yaitu dengan menghitung tanaman hias yang terjual dikali dengan harga pertanaman hias yang terjual. Adapun Rumus yang digunakan untuk menghitung total penerimaan menurut Soedarsono (1992); Soekartawi (1990); Samuelson \& Nordhaus (2003) yaitu sebagai berikut:

$$
\mathrm{TR}=\mathrm{Pq} \cdot \mathrm{Q} \text {. }
$$

dimana TR adalah total penerimaan, $\mathrm{Q}$ adalah jumlah tanaman yang terjual, dan Pq adalah harga tanaman.

Selanjutnya untuk mengetahui pendapatan yaitu dilakukan dengan 
menghitung jumlah penerimaan dikurangi dengan jumlah biaya yang dikeluarkan perbulan daripada kegiatan usaha tanaman hias. Adapun rumus yang digunakan untuk mengetahui pendapatan menurut Boediono (1999); Soedarsono (1992); Soekartawi (1990) yaitu sebagai berikut:

$$
\mathrm{I}=\mathrm{TR}-\mathrm{TC} \text {. }
$$

dimana I adalah income (pendapatan). Untuk mengetahui kelayakan usaha menggunakan rumus Soedarsono (1992); Soekartawi (1990) sebagai berikut:

R/C Ratio

dengan kriteria jika :

R/C Ratio > 1, menguntungkan

$\mathrm{R} / \mathrm{C}$ Ratio $=1$, (impas)

$\mathrm{R} / \mathrm{C}$ Ratio $<1$, tidak menguntungkan

\section{HASIL PENELITIAN}

Salah satu faktor penting dalam pengelolaan usaha tanaman hias adalah biaya. Besarnya biaya usaha yang dikeluarkan untuk memproduksi sesuatu, juga menentukan besarnya harga produk dan produk yang akan dihasilkan. Dengan demikian besar kecilnya biaya akan menentukan pula besar kecilnya pendapatan yang diterima pengusaha. Biaya pada usaha tanaman hias "UD. Rahma Nurseri" terdiri dari dua jenis yaitu biaya tetap dan biaya variabel. Penjumlahan dua jenis biaya tersebut akan diperoleh biaya total dari usaha tanaman hias "Rahma Nurseri" selama sebulan. Dari hasil penelitian menunjukan bahwa biaya yang dikeluarkan selama produksi berlangsung (per bulan) disajikan pada Tabel 1:

Tabel 1. Biaya Usaha Tanaman Hias UD Rahma Nurseri

\begin{tabular}{|c|c|c|c|c|}
\hline Jenis Biaya & $\begin{array}{l}\text { Biaya Bunga } \\
\text { Aggrek (Rp) }\end{array}$ & $\begin{array}{l}\text { Biaya Bunga } \\
\text { Melati (Rp) }\end{array}$ & $\begin{array}{l}\text { Biaya Bunga } \\
\text { Srirezeki (Rp) }\end{array}$ & $\begin{array}{l}\text { Biaya Bunga } \\
\text { Anthorium (Rp) }\end{array}$ \\
\hline \multicolumn{5}{|l|}{ Biaya Variabel : } \\
\hline Pot & 100.000 & 200.000 & 350.000 & 100.000 \\
\hline Sabut Kelapa & 25.000 & & & \\
\hline Arang & 20.000 & & & \\
\hline Obat-obatan & 35.000 & 35.000 & 50.000 & 25.000 \\
\hline Tenaga kerja & 350.000 & 350.000 & 350.000 & 350.000 \\
\hline Bibit & 500.000 & 850.000 & 1.500 .000 & 500.000 \\
\hline Polibag & & 20.000 & 50.000 & 20.000 \\
\hline Pupuk & & 80.000 & 100.000 & 50.000 \\
\hline Sekam padi & & 25.000 & 50.000 & 25.000 \\
\hline Total Biaya Variabel & 1.030 .000 & 1.560 .000 & 2.450 .000 & 1.070 .000 \\
\hline \multicolumn{5}{|l|}{ Biaya Tetap : } \\
\hline Listrik & 15.000 & 15.000 & 15.000 & 15.000 \\
\hline Air & 20.000 & 20.000 & 40.000 & 20.000 \\
\hline Pemeliharaan & 115.000 & 115.000 & 150.000 & 115.000 \\
\hline Supplier & 25.000 & 25.000 & 50.000 & 25.000 \\
\hline Lain-lain & 200.000 & 200.000 & 200.000 & 200.000 \\
\hline Total Biaya Tetap & 375.000 & 375.000 & 445.000 & 375.000 \\
\hline Total Biaya & 1.405 .000 & 1.935 .000 & 2.895 .000 & 1.445 .000 \\
\hline Biaya Keseluruhan & \multicolumn{4}{|c|}{7.680 .000} \\
\hline
\end{tabular}

Tabel 1 menunjukkan total biaya usaha bunga anggrek yaitu sebesar $\mathrm{Rp}$ 1.405.000, biaya usaha bunga melati sebesar Rp 1.935.000, biaya usaha bunga srirezeki sebesar Rp 2.895.000, dan biaya usaha bunga anthorium sebesar $\mathrm{Rp}$ 
1.445.000. Dari keempat jenis tanaman hias tersebut ditemukan biaya usaha yang terbesar yaitu bunga sri rezeki, menyusul bunga melati, bunga anthorium dan bunga anggrek. Biaya usaha tanaman hias tersebut terdiri dari biaya variabel dan biaya tetap. Ditinjau dari besaran biaya tetap keempat jenis tanaman hias tersebut diperoleh relatif sama besarnya, sedangkan ditinjau dari biaya variabel terdapat perbedaan yang relatif besar. hal ini ditentukan besaran biaya bibit dari masing-masing jenis tanaman.

Total biaya usaha tanaman hias "UD. Rahma Nurseri” perbulan yaitu penjumlahan dari biaya usaha bunga anggrek, bunga melati, bunga srirezeki, dan bunga anthorium. Hasil penjumlahan biaya tersebut diperoleh sebesar $\mathrm{Rp}$. 7.680.000. Berdasarkan kegiatan usaha tanaman hias UD Rahma Nurseri diperoleh penerimaan sebagaimana disajikan pada Tabel 2.

Tabel 2. Penerimaan Usaha Tanaman Hias UD Rahma Nurseri

\begin{tabular}{lccc}
\hline Jenis Tanaman & Jumlah Penjualan (unit) & Harga (Rp) & Penerimaan (Rp) \\
\hline Bunga Anggrek & 30 & 100.000 & 3.500 .000 \\
Binga Melati & 50 & 75.000 & 3.750 .000 \\
Bunga Srirezeki & 125 & 35.000 & 4.375 .000 \\
Bunga Anthorium & 200 & 15.000 & 3.000 .000 \\
\hline Jumlah Penerimaan & 375 & & 14.625 .000 \\
\hline
\end{tabular}

Sumber: data Primer diolah Tahun 2019

Tabel 2 menunjukkan penerimaan usaha tanaman hias "UD. Rahma Nurseri" adalah sebesar Rp 14.625.000. Nilai ini diperoleh dari penjumlahan penjualan bunga anggrek sebesar Rp. 3.500.000, bunga melati sebesar Rp3.750.000, bunga srirezeki sebesar Rp 4.375.000, dan bunga anthorium sebesar Rp 3.000.000. Dari keempat penerimaan jenis tanaman hias tersebut diketahui bahwa jumlah penjualan terbanyak adalah jenis bunga anthorium, tetapi nilai penerimaannya paling rendah, sedangkan penerimaan paling besar yaitu hasil penjualan jenis bunga srirezeki, sementara penjualan jenis bunga anggrek jumlah penjualannya paling sedikit. Dilihat dari harga penjualan dari keempat jenis bunga tersebut, maka jenis bunga anggrek merupakan jenis bunga yang relatif paling mahal dibanding ketiga jenis bunga yang lain. Hal ini dapat disimpulkan bahwa jenis bunga anggrek paling sedikit peminatnya karena harganyarelatif paling besar sedangkan bunga anthorium paling banyak peminatnya karena harganya relatif paling murah.

Dari hasil perhitungan total biaya dan total penerimaan, maka dapat diketahui pendapatan usaha tanaman hias UD Rahma Nurseri. Besar kecilnya pendapatan tersebut dapat diketahui dari selisih antara total biaya dan total penerimaan. Adapun hasil perhitungan besarnya pendapatan usaha tanaman hias UD Rahma Nurseri disajikan pada Tabel 3: 
Tabel 2. Pendapatan dan R/C Ratio Usaha Tanaman Hias UD Rahma Nurseri

\begin{tabular}{lccc}
\hline Jenis Tanaman & Biaya Usaha $(\mathrm{Rp})$ & Penerimaan $(\mathrm{Rp})$ & Pendapatan $(\mathrm{Rp})$ \\
\hline Bunga Anggrek & 1.405 .000 & 3.500 .000 & 2.095 .000 \\
Binga Melati & 1.935 .000 & 3.750 .000 & 1.815 .000 \\
Bunga Srirezeki & 2.895 .000 & 4.375 .000 & 1.480 .000 \\
Bunga Anthorium & 1.445 .000 & 3.000 .000 & 1.555 .000 \\
\hline Jumlah & 7.680 .000 & 14.625 .000 & 6.945 .000 \\
\hline R/C Ratio & 1,9 & \\
\multicolumn{2}{c}{ Sumber : Data Primer Diolah 2019 } &
\end{tabular}

Pada Tabel 3 menunjukkan pendapatan jenis bunga anggrek yaitu sebesar Rp 2.095.000, pendapatan bunga melati sebesar Rp 1.815.000, pendapatan bunga srirezeki sebesar Rp 1. 480.000, dan pendapatan bunga anthorium sebesar Rp. 1.555.000. Berdasarkan keempat jenis tanaman hias tersebut, diketahi pendapatan bunga anggrek relatif paling besar, menyusul bunga melati, bunga anthorium, dan paling rendah bunga srirezeki. Tingginya pendapatan jenis bungga anggrek ini dapat disebabkan harga dari jenis bunga tersebut relatif mahal, dibanding jenis bunga lainnya. Secara keseluruhan pendapatan usaha tanaman hias UD Rahma Nurseri diperoleh sebesar Rp. 6.945.000 perbulan. Hal ini menunjukan bahwa kegiatan usaha tanaman hias UD Rahma Nurseri menguntungkan. Depritos (2016), menemukan rata-rata keuntungan usaha tanaman hias yaitu sebesar 21.503.688/tahun. Hasil penelitian Fatmawati dkk. (2020), menemukan bahwa biaya tenaga kerja, harga beli, sekam dan biaya transportasi mempengaruhi pendapatan tanaman hias, sedangkan Setiana, (2016), melaporkan bahwa pendapatan berhubungan positif dengan ketersediaan modal, musim dan jenis barang.

Dalam rangka meningkatkan pendapatan usaha tanaman hias pada UD Rahma Nurseri perlu melakukan kerjasama dengan pedagang bunga. Hal ini diharapkan untuk meningkatkan penjualan bunga yang diusahakan. Kerjasama tersebut perlu mempertimbangkan kemampuan pedagang tanaman hias mulai dari modal, pengalaman dan harga. Menurut Wiharyati (2014) modal, pengalaman usaha, jam kerja, jenis bunga dan jenis pedagang berpengaruh terhadap pendapatan pedagang bunga. Hal ini akan berkaitan dengan serapan pembelian tanaman hias pada usaha UD Rahma Nurseri.

Berdasarkan hasil perhitungan R/C ratio diketahui nilai $\mathrm{R} / \mathrm{C}$ ratio yaitu sebesar 1,9. Nilai ini dapat dimaknai bahwa, setiap pengeluaran Rp 1 dapat memberikan keuntungan sebesar Rp 0,9. Tingkat kelayakan usaha tersebut memberikan gambaran bahwa UD Rahma Nurseri dapat mengembangkan usaha tanaman hiasnya lebih besar lagi.

\section{KESIMPULAN}

Berdasarkan hasil penelitian dan pembahasan yang telah diuraikan, maka dapat disimpulkan kegiatan usaha tanaman hias "UD. Rahma Nurseri" yang bertempat di Desa Bangunsari memberikan pendapatan sebesar Rp. 7.625.000 perbulan dengan total biaya yang dikeluarkan sebesar Rp 14.625.000. Tingkat kelayakan usaha tersebut yaitu sebesar 1,9 yang berarti setiap 
pengeluaran sebesar $\mathrm{Rp} 1$, dapat memberikan pendapatan sebesar Rp 0,9.

\section{DAFTAR PUSTAKA}

Boediono, D. R. (1999). Seri Sinopsis Pengantar Ilmu Ekonomi No. 1 Ekonomi Mikro. BPFE, Edisi, 2.

Depritos, D. (2016). Analisis Pendapatan Usahatani Tanaman Hias di Kawasan Agrowisata Kelurahan Lubuk Minturun Sungai Lareh Kecamatan Koto Tangan Kota Padang. STKIP PGRI SUMATERA BARAT.

DEWANTI, R., \& Sudarman, A. (2001). Pertumbuhan ekonomi dan kesempatan kerja Propinsi Daerah Khusus Ibukota Jakarta:: Suatu penerapan model rasio pertumbuhan. [Yogyakarta]: Universitas Gadjah Mada.

Fatmawati, E., Astuti, A., \& Widiatmi, S. (2020). ANALISIS FAKTORFAKTOR YANG MEMPENGARUHI PENDAPATAN USAHA TANAMAN HIAS DI PASTY KOTA YOGYAKARTA. JURNAL
ILMIAH AGRITAS, 3(2), 1-11.

Samuelson, P., \& Nordhaus, W. D. (2003). Ilmu Mikroekonomi, terj. Nur Rosyidah, Anna Elly Dan BoscoCarvallo. PT Media Global Edukasi, Jakarta.

Setiana, D. (2016). Analisis Pendapatan Usaha Pada Pedagang Tanaman Hias Di Kelurahan Gunung Terang Bandar Lampung.

Soedarsono. (1992). Pengantar ekonomi mikro. Retrieved from https://books.google.co.id/books?id $=$ TCabAAAACAAJ

Soekartawi, A. (1990). Prinsip-Prinsip Dasar Ekonomi Pertanian. Teori Dan Aplikasi. RajaGrafindo Persada. Jakarta.

Wiharyati, S. (2014). Analisis FaktorFaktor Yang Mempengaruhi Tingkat Pendapatan Pedagang Bunga Di Agrowisata Tanaman Hias Nglurah Kelurahan Tawangmangu Kecamatan Tawangmangu Kabupaten Karanganyar Tahun 2012. 